\title{
Early extubation after left ventricular assist device implantation in a patient with Duchenne muscular dystrophy: a case report
}

\author{
Hye-Jin Kim ${ }^{1}$ - Soo-Yeon $\mathrm{Kim}^{2}$ • Min Ho Ju${ }^{3}$. Soo Yong Lee ${ }^{4}$ Gyeong-Jo Byeon ${ }^{1,5} \cdot$ Hee Young Kim ${ }^{1}$ (I)
}

Received: 29 January 2021 / Accepted: 13 March 2021 / Published online: 29 March 2021

(c) Japanese Society of Anesthesiologists 2021

\begin{abstract}
Management of Duchenne muscular dystrophy (DMD) cardiomyopathy is increasingly important for the survival of these patients. Left ventricular assist device (LVAD) is an alternative treatment for refractory heart failure in DMD. A 20-year-old man with DMD and dilated cardiomyopathy underwent surgery for LVAD implantation. Respiratory failure may occur due to muscle weakness after surgery under general anesthesia in patients with DMD, and weaning from mechanical ventilation may be delayed or difficult. Considering the application of fast-track anesthesia (FTA), preoperative pulmonary rehabilitation which includes thoracic expansion exercise, air stacking exercise with manual resuscitation bag and manually assisted cough technique, hight-frequency chest wall oscillation, and mechanical insufflation-exsufflation was performed. We report on a patient with DMD in whom FTA and early extubation within $6 \mathrm{~h}$ after LVAD implantation was successfully performed without complications.
\end{abstract}

Keywords Anesthesia · Dilated cardiomyopathy · Duchenne muscular dystrophy $\cdot$ Enhanced recovery after surgery Ventricular assist device $\cdot$ Rehabilitation

Hee Young Kim

anekhy@gmail.com

1 Department of Anesthesia and Pain Medicine, Pusan National University, Yangsan Hospital, 20 Geumo-ro, Beomeo-ri, Mulgeumeup, Yangsan 50612, Republic of Korea

2 Rehabilitation Medicine, Pusan National University School of Medicine and Research Institute for Convergence of Biomedical Science and Technology, Pusan National University, Yangsan Hospital, Yangsan, Republic of Korea

3 Department of Cardiovascular and Thoracic Surgery, Pusan National University, Yangsan Hospital, Yangsan, Republic of Korea

4 Division of Cardiology, Department of Internal Medicine, Research Institute for Convergence of Biomedical Science and Technology, Pusan National University, Yangsan Hospital, Yangsan, Republic of Korea

5 Department of Anesthesia and Pain Medicine, School of Medicine, Pusan National University, Yangsan, Republic of Korea

\section{Introduction}

Duchenne muscular dystrophy (DMD) is an X-linked recessive disease, accounts for $80-85 \%$ of all muscular dystrophy, and occurs in 1 in 3500 male newborns [1]. Most patients with DMD cannot walk at age 10 and are walker dependent. Death occurs before age 20 due to heart and respiratory muscle involvement [2, 3]. Previously, respiratory insufficiency was the leading cause of death; however, with the development of ventilator support, it was replaced by cardiac complications such as dilated cardiomyopathy (DCM) [4]. Therefore, management of DMD cardiomyopathy is increasingly important for the survival of these patients.

However, DMD cardiomyopathy has higher mortality than other DCMs [5], and heart transplantation is contraindicated in dystrophinopathies as it may cause respiratory failure and limited functional capacity due to progressive skeletal myopathy $[6,7]$. Left ventricular assist device (LVAD) is an alternative treatment for refractory heart failure in DMD $[8,9]$. Fast-track anesthesia (FTA) for LVAD implantation with appropriate patient selection reportedly resulted in fewer postoperative complications [10].

We report on the successful and uncomplicated performance of FTA and early extubation within $6 \mathrm{~h}$ of LVAD 
implantation in a patient with DMD and INTERMACS (Interagency Registry for Mechanically Assisted Circulatory Support) level 3 DCM (Table 1). Written informed consent for publication was obtained from the parent as the patient was immobile.

\section{Case}

A 20-year-old man (height: $138 \mathrm{~cm}$, weight: $39 \mathrm{~kg}$ ) diagnosed with DMD at age 11 was hospitalized for heart failure and dyspnea due to DCM and ischemic cardiomyopathy. He had a history of atrial flutter and underwent left proximal circumflex artery balloon angioplasty for acute embolic myocardial infarction 1 year ago. Despite volume reduction and inotrope use (dobutamine, $3 \mathrm{mcg} / \mathrm{kg} / \mathrm{min}$ ), his blood pressure was maintained at $85-100 / 55-60 \mathrm{mmHg}$, and ejection fraction was $24 \%$. He had INTERMACS level 3 DCM. HeartMate 3 LVAD (St Jude Medical Inc., St Paul, MN) implantation was planned.

Preoperatively, his B-type natriuretic peptide level was $3803 \mathrm{pg} / \mathrm{ml}$, and sinus rhythm was maintained. Chest radiography showed cardiomegaly and lumbar scoliosis (Fig. 1). Transthoracic echocardiography revealed left ventricular (LV) apex, basal anterior wall, and mid to basal posterolateral wall akinesia with severe LV systolic dysfunction. Pulmonary function test results showed a severe restrictive pattern with forced vital capacity of $0.75 \mathrm{~L}(26 \%$ of predicted value). The patient was unable to ambulate, and difficult intubation was anticipated due to postural abnormalities (short neck, small chin, and severe scoliosis). The cardiologist, thoracic surgeon, physiatrist, and anesthesiologist emphasized the importance of postoperative respiratory function recovery, and a pulmonary rehabilitation program was conducted preoperatively to allow early extubation postoperatively. Thoracic expansion exercise, air stacking exercise with manual resuscitation bag (Ambu. bag; Hudson respiratory care Inc., Temecula, CA, USA) and manually assisted cough technique were performed for pulmonary rehabilitation program. High-frequency chest wall

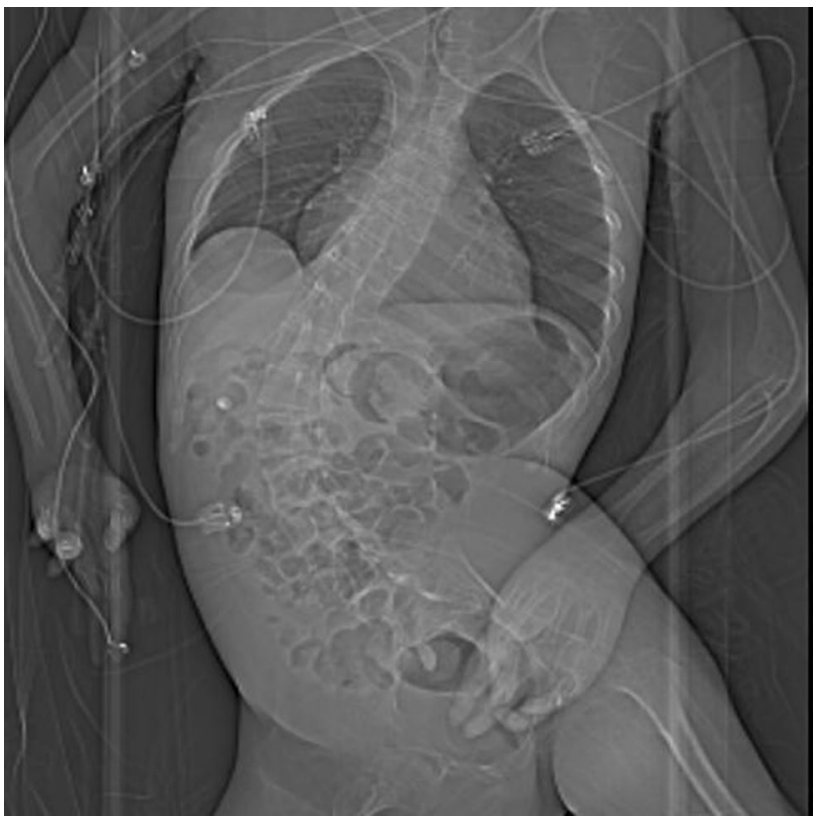

Fig. 1 Preoperative chest X-ray. The patient has severe lumbar scoliosis

oscillation (The Vest ${ }^{\circledR}$ Airway Clearance System, Model 105, Hillrom, USA) and mechanical insufflation-exsufflation device (CoughAssist T70, Philips) were also applied for pulmonary hygiene. Unfortunately, only tiny objective improvement of respiratory function (forced vital capacity of $0.77 \mathrm{~L}, 27 \%$ of predicted value) was confirmed (forced vital capacity of $0.75 \mathrm{~L}$ ( $26 \%$ of predicted value).

Immediately preoperatively, the patient's blood pressure was $83 / 60 \mathrm{mmHg}$, heart rate was 108 beats per minute, and oxygen saturation was $100 \%$ on room air. Total intravenous anesthesia with $2 \%$ propofol and $0.05 \%$ remifentanil was performed considering the risk of malignant hyperthermia. Video laryngoscopy was performed, because difficult intubation was expected. After continuous infusion of propofol $(4 \mathrm{mcg} / \mathrm{ml})$ and remifentanil $(3 \mathrm{ng} / \mathrm{ml})$ for $5 \mathrm{~min}$, and bolus injection of $40 \mathrm{mg}$ rocuronium, intubation was successfully performed. Blood pressure was maintained
Table 1 INTERMACS classification

\begin{tabular}{ll}
\hline INTERMACS profile & Description \\
\hline Level 1 & Critical cardiogenic shock. "Crash and Burn" \\
Level 2 & Progressive decline. "Sliding fast on inotropes" \\
Level 3 & "Stable" continuous inotrope dependent. Can be in hospital or at home \\
Level 4 & Resting symptoms on oral therapy at home \\
Level 5 & Exertion intolerant. "Housebound" comfortable at rest, symptoms \\
& with minimum activities of daily living (ADL) \\
Level 6 & "Walking wounded"-ADL possible but meaningful activity limited \\
Level 7 & Advanced classification II \\
\hline
\end{tabular}

INTERMACS Interagency Registry for Mechanically Assisted Circulatory Support 
at $80-100 / 40-60 \mathrm{mmHg}$ using dobutamine $(10 \mathrm{mcg} / \mathrm{kg} /$ $\mathrm{min})$ and norepinephrine $(0.1 \mathrm{mcg} / \mathrm{kg} / \mathrm{min})$. A target-controlled infusion pump infused propofol $(2-2.5 \mathrm{mcg} / \mathrm{ml})$ and remifentanil (1-2 ng/ml) (bispectral index value 40-60). Rocuronium ( $2 \mathrm{mcg} / \mathrm{kg} / \mathrm{min})$ was continuously infused. Initially, regional cerebral oxygen saturation was 30-35, but was maintained at 45-70 from cardiopulmonary bypass (CPB) to surgery completion.

Surgery was performed via median sternotomy on the beating heart under CPB. The surgeon docked the inflow cannula on the LV apex, made a tunnel for the driveline, and anastomosed the outflow graft and aorta (Fig. 2). After bleeding control with deairing, the patient was weaned from CPB by carefully increasing the LVAD speed. Mean arterial blood pressure was maintained at $70-80 \mathrm{mmHg}$ using dobutamine $(3 \mathrm{mcg} / \mathrm{kg} / \mathrm{min})$, norepinephrine $(0.1 \mathrm{mcg} / \mathrm{kg} /$ $\mathrm{min})$ and milrinone $(0.75 \mathrm{mcg} / \mathrm{kg} / \mathrm{min})$ during post-CPB period. Rocuronium infusion was stopped $45 \mathrm{~min}$ before surgery completion. Before transferring, infusion of propofol and remifentanil was stopped, and intravenous patient controlled analgesia which contains $1000 \mathrm{mcg}$ of fentanyl, and $0.3 \mathrm{mg}$ of ramosetron in $100 \mathrm{ml}$ was started. Immediately after being transferred to the intensive care unit, the patient obeyed a simple command. One hour before extubation, oxygen saturation was maintained $94-96 \%$ with pressure support ventilation (fraction of oxygen $50 \%$, pressure $9 \mathrm{cmH}_{2} \mathrm{O}$, and PEEP $5 \mathrm{cmH}_{2} \mathrm{O}$ ). Extubation was performed under the supervision of a cardiologist, physiatrist, and anesthesiologist $4 \mathrm{~h}$ postoperatively. Mechanical insufflation-exsufflation

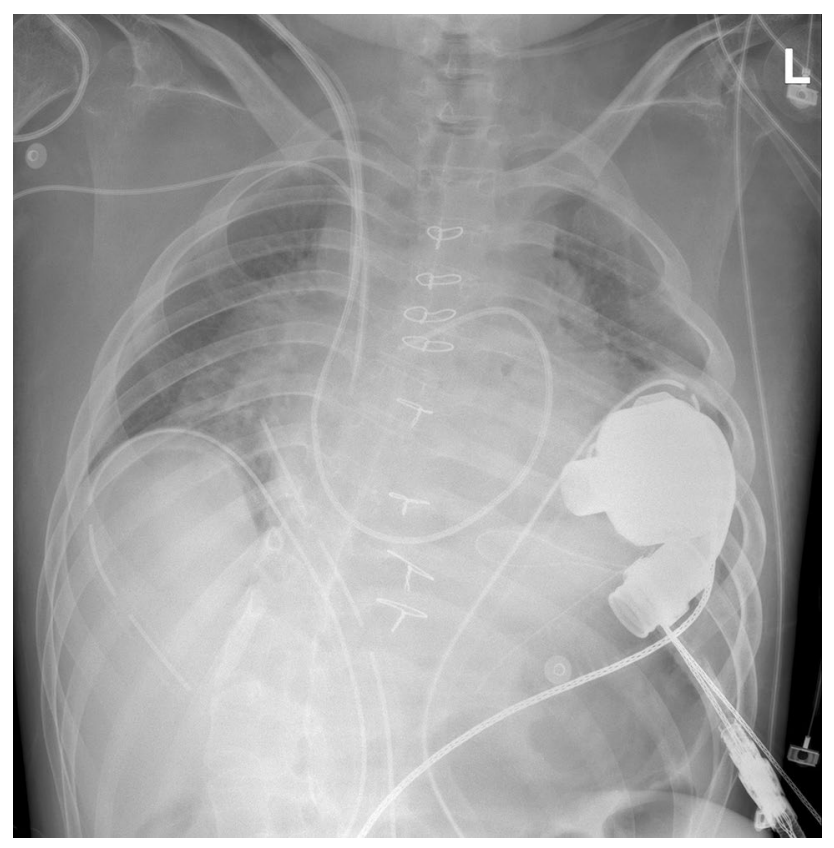

Fig. 2 Postoperative chest X-ray. LAVD is well located on the left chest. $L A V D$ left ventricular assist device device with pressure of $+40 \mathrm{cmH}_{2} \mathrm{O} /-40 \mathrm{cmH}_{2} \mathrm{O}$ was used 5 cycles for pulmonary hygiene before extubation. Immediately postextubation, oxygen saturation was maintained $99 \%$ with oxygen $2 \mathrm{~L} / \mathrm{min}$ via nasal cannula, and the result of arterial blood gas analysis showed $\mathrm{PaO}_{2} 90 \mathrm{mmHg}, \mathrm{PaCO}_{2}$ $52 \mathrm{mmHg}$, and $\mathrm{pH}$ 7.31. Somnolence and carbon dioxide retention (up to $54 \mathrm{mmHg}, \mathrm{pH} 7.33$ ) was observed, which recovered to $43 \mathrm{mmHg}$, $\mathrm{pH} 7.36$ on the next day. The LVAD pump speed was maintained at 5000 revolutions per minute and pump flow at $2.5-3 \mathrm{~L} / \mathrm{min}$. The patient was transferred to a general ward 6 days postoperatively and received dobutamine (1-3 $\mathrm{mcg} / \mathrm{kg} / \mathrm{min})$ without complications.

\section{Discussion}

Patients with DMD die from respiratory or heart failure before age 29 , with more than $50 \%$ having DCM by age 15 $[11,12]$. In these patients, heart failure is medically treated using angiotensin converting enzyme inhibitors and steroids, which reduces mortality $[13,14]$. Despite this, most patients eventually experience progressive cardiac dysfunction and require heart transplantation, which has little evidence [15], or LVAD implantation, which is useful as destination therapy $[8,9,11]$. Our patient, a 20-year-old with INTERMACS level 3 DCM, was unable to exercise spontaneously, but had good spontaneous breathing. Therefore, LVAD implantation was planned.

Malignant hyperthermia may occur when inhaled anesthetics and succinylcholine are used in patients with DMD, leading to rhabdomyolysis and hyperkalemic cardiac arrest. Additionally, they may have a difficult airway and sensitivity to neuromuscular blockers [16]. Therefore, total intravenous anesthesia (TIVA) is commonly performed using propofol and remifentanil, which are known to be safe, with nondepolarizing neuromuscular blocker administration if necessary [16]. We performed TIVA with video laryngoscopic intubation due to anticipated difficult intubation. Although no clinically evident respiratory impairments were observed, we should have performed neuromuscular monitoring such as train-of-four or double-burst stimulation during recovery after rocuronium administration.

Respiratory failure may occur due to muscle weakness after surgery under general anesthesia in patients with DMD, causing delayed or difficult weaning from mechanical ventilation (MV). Additionally, although MV has an unloading effect on respiratory muscles, it causes diaphragmatic atrophy and dysfunction, which is known as ventilator-induced diaphragmatic dysfunction (VIDD) [17]. Since VIDD affects weaning, early extubation using non-invasive ventilation and pulmonary rehabilitation is important [17]. Additionally, postoperative complications such as respiratory failure, prolonged MV, psychiatric events, and right ventricular 
failure (RVF) can lead to high morbidity and mortality [18]. Feasibility of ultra-fast-track anesthesia with in-theater extubation (UFTA) has been studied in patients with heart transplantation and LVAD implantation [10, 19]. Patients with INTERMACS level 3-4 undergoing LVAD implantation showed better hemodynamic performance and lower RVF frequency following UFTA [10]. Our patient underwent preoperative pulmonary rehabilitation to prepare for UFTA and was successfully extubated in the intensive care unit $4 \mathrm{~h}$ postoperatively under the supervision of a cardiologist, physiatrist, and anesthesiologist.

In conclusion, LVAD implantation is useful as destination therapy for heart failure in patients with DMD, who have few therapeutic options. A multidisciplinary approach including cardiology, thoracic surgery (surgical access method), rehabilitation medicine (pulmonary rehabilitation), and anesthesia and pain medicine (selection of anesthetic drugs) is required while planning surgery. Additionally, rapid weaning from MV using UFTA can be attempted.

Author contributions H-JK, and KHY: study conception and design, acquisition, analysis and interpretation of data, drafting the article, revising it critically for important intellectual content; H-JK, S-YK, MHJ, SYL, G-JB, KHY: acquisition, revising the article critically for important intellectual content. All authors read and approved the final manuscript, and agreed to be accountable for all aspects of the work.

Funding This work was supported by a 2021 research grant from Pusan National University Yangsan Hospital.

\section{Declarations}

Conflict of interest The authors declare that they have no conflict of interest.

\section{References}

1. Finsterer J, Stöllberger CJC. The heart in human dystrophinopathies. Cardiology. 2003;99(1):1-19.

2. Boland BJ, Silbert PL, Groover RV, Wollan PC, Silverstein MD. Skeletal, cardiac, and smooth muscle failure in Duchenne muscular dystrophy. Pediatric Neurol. 1996;14(1):7-12.

3. Choi J, Song K, Park SJ. Genetic polymorphism analysis for the detection of Duchenne muscular dystrohpy carriers. Korean J Clin Pathol. 2000;20:236-41.

4. Fayssoil A, Nardi O, Orlikowski D, Annane DJ. Cardiomyopathy in Duchenne muscular dystrophy: pathogenesis and therapeutics. Heart Failure Rev. 2010;15(1):103.

5. McNally EM, Kaltman JR, Benson DW, Canter CE, Cripe LH, Duan D, Finder JD, Groh WJ, Hoffman EP, Judge DP, Kertesz N, Kinnett K, Kirsch R, Metzger JM, Pearson GD, Rafael-Fortney JA, Raman SV, Spurney CF, Targum SL, Wagner KR, and Markham LW. Contemporary cardiac issues in Duchenne muscular dystrophy. Circulation. 2015;131(18):1590-8.

6. Chun JL, O'Brien R, Berry SE. Cardiac dysfunction and pathology in the dystrophin and utrophin-deficient mouse during development of dilated cardiomyopathy. Neuromuscul Disord. 2012;22(4):368-79.

7. Wu RS, Gupta S, Brown RN, Yancy CW, Wald JW, Kaiser P, Kirklin NM, Patel PC, Markham DW, Drazner MH, Garry DJ, Mammen PPA. Clinical outcomes after cardiac transplantation in muscular dystrophy patients. J Heart Lung Transplant. 2010;29(4):432-8.

8. Stoller D, Araj F, Amin A, Fitzsimmons C, Morlend R, Thibodeau JT, Ramaciotti C, Drazner MH, Meyer DM, Mammen PPA. Implantation of a left ventricular assist device to provide long-term support for end-stage Duchenne muscular dystrophyassociated cardiomyopathy. ESC Heart Failure. 2017;4(3):379-83.

9. Perri G, Filippelli S, Adorisio R, Iacobelli R, Iodice F, Testa G, Paglietti MG, D'Amario D, Massetti M, Amodeo A. Left ventricular assist device as destination therapy in cardiac end-stage dystrophinopathies: midterm results. J Thorac Cardiovasc Surg. 2017;153(3):669-74.

10. Zayat R, Menon AK, Goetzenich A, Schaelte G, Autschbach R, Stoppe C, Simon T-P, Tewarie L, Moza A. Benefits of ultra-fasttrack anesthesia in left ventricular assist device implantation: a retrospective, propensity score matched cohort study of a fouryear single center experience. J Cardiothorac Surg. 2017;12(1):10.

11. Ryan TD, Jefferies JL, Sawnani H, Wong BL, Gardner A, Del Corral M, Lorts A, Morales DLS. Implantation of the HeartMate II and HeartWare left ventricular assist devices in patients with Duchenne muscular dystrophy: lessons learned from the first applications. ASAIO J. 2014;60(2):246-8.

12. Morris P. Duchenne muscular dystrophy: a challenge for the anaesthetist. Wiley Online Library; 1997.

13. Duboc D, Meune C, Lerebours G, Devaux J-Y, Vaksmann G, Bécane H-MJ. Effect of perindopril on the onset and progression of left ventricular dysfunction in Duchenne muscular dystrophy. J Am College Cardiol. 2005;45(6):855-7.

14. Schram G, Fournier A, Leduc H, Dahdah N, Therien J, Vanasse M, Khaiy P. All-cause mortality and cardiovascular outcomes with prophylactic steroid therapy in Duchenne muscular dystrophy. J Am Coll Cardiol. 2013;61(9):948-54.

15. de Kermadec J-M, Becane H-M, Chenard A, Tertrain F, Weiss YJ. Prevalence of left ventricular systolic dysfunction in Duchenne muscular dystrophy: an echocardiographic study. Am Heart J. 1994;127(3):618-23.

16. Muenster T, Mueller C, Forst J, Huber H, Schmitt HJ. Anaesthetic management in patients with Duchenne muscular dystrophy undergoing orthopaedic surgery: a review of 232 cases. Eur J Anaesthesiol. 2012;29(10):489-94.

17. Grosu HB, Im Lee Y, Lee J, Eden E, Eikermann M, Rose KMJC. Diaphragm muscle thinning in patients who are mechanically ventilated. Chest. 2012;142(6):1455-60.

18. Kormos RL, Teuteberg JJ, Pagani FD, Russell SD, John R, Miller LW, Massey T, Milano CA, Moazami N, Sundareswaran KS, Farra DJ. Right ventricular failure in patients with the HeartMate II continuous-flow left ventricular assist device: incidence, risk factors, and effect on outcomes. J Thorac Cardiovasc Surg. 2010;139(5):1316-24.

19. Kianfar AA, Ahmadi ZH, Mirhossein SM, Jamaati H, Kashani BS, Mohajerani SA, Firoozi E, Salehi F, Radmand G, Hashemian SM. Ultra fast-track extubation in heart transplant surgery patients. Int J Crit Illn Inj Sci. 2015;5(2):89.

Publisher's Note Springer Nature remains neutral with regard to jurisdictional claims in published maps and institutional affiliations. 